\title{
Processes of Allocation to Open and Closed Positions in Social Structure*
}

\author{
Aage B. Sфrensen \\ University of Wisconsin-Madison, Department of Sociology \\ Madison, WI 53706, USA
}

\begin{abstract}
A b s t r a c t: This paper analyses mechanisms of allocation to closed positions in social structure. Closed positions are characterized by only being available when vacated by the previous incumbent, so that new allocations resulting in new matches between people and persons cannot be linked to changes in performance or the availability of more qualified candidates. The mechanism of allocation in closed position systems, called vacancy competition, is contrasted to the allocated mechanism operating in open position systems that are competitive markets. The paper presents conceptual and methodological implications of vacancy competition for research on the labor market and on ailocation to instructional groups in schools.
\end{abstract}

\section{Introduction}

Certain sociologists might, at times, doubt whether or not they are doing sociology. Quantitative sociologists, relying heavily on sample surveys, tend to use individuals as units of analysis, and they engage in causal analysis of individual level outcomes determined by individual level antecedents formed by past experiences and demographic characteristics. It is often difficult, if not impossible, to differentiate sociologists engaged in such pursuits from social psycholo. gists, when focusing on mental states; and from economists, when focusing on socioeconomic outcomes.

The boundary between sociology and social psychology is blurred for a number of reasons other than the design of survey research. Even when the boundary is emphasized, social psychologists can usually be counted on to cooperate and to collaborate rather than to compete for grants, recognition, and academic resources. This is not so with respect to economists. Here the boundary is sharp. There are few overlaps

* This paper was completed while the author was Guest Professor at the Zentrum fuir Umfragen, Methoden und Analysen in Mannheim, Fall 1982. Additional support was obtained from the Graduate School Research Committee at the University of Wisconsin-Madison, and from grants to the Institute for Research on Poverty from the National Institute on Aging (grant AGO 2816-02) and to the Wisconsin Center for Education Research from the National Institute of Education (grant NIE6810009). Valuable comments on earlier drafts of this article were provided by Kart-Ulrich Mayer, Rachel Rosenfeld, Arthur Stinchcombe and Annemette Sorensen. Errors and opinions only reflect the author. in curricula, in publication outlets, and in personel. To make matters worse for sociologists, economists are known to consider economics the Queen of the social sciences, and some economists have been heard whispering that there are few sociological problems a bit of economic theory could not straighten out.

Grand sociological theory sees the economy as a subsystem of the social system. But, grand sociological theory usually does not deal with individual level outcomes; it is here the boundary problem is most acutely felt. $A$ large and important sociological literature, where this boundary problem is present, has come into being over the last 15 years. This literature is on the determinants of socioeconomic outcomes of individuals, measured in occupational status, income, or earnings. The first wave of this research focused on the intergenerational transmission of personal resources important for individual socioeconomic outcomes. The start is usually dated to Blau and Duncan (1967). The second and current wave, emphasizes the importance of labor market structures, in the form of dual or segmented labor markets, for socioeconomic outcomes. In this research, "structural" variables are added to the background variables employed in the first wave of sociological attainment research. (For a review, see Kalleberg/ Sorensen 1979.)

Socioeconomic attainment research has been a successful enterprise in sociology. It is perhaps the closest thing to "normal science" in the discipline. There is quite a bit of apparent cumulation of knowledge; publications replicating earlier research or introducing additional varia- 
bles; and, disputes over measurement procedures and the proper role of variables in causal sequences. The area has its critics and detractors: the emergence of labor market research to replace status attainment research has been argued to represent a change of paradigm (e.g. Beck et al. 1980). It seems, however, the second wave of attainment research primarily represents the addition of a new set of variables. No fundamental change in the structure of models employed, or in the basic conception of what goes on, seems implied by the new sociology of labor markets. In fact, the sociology of labor markets and the earlier status attainment research share a lack of attention to conceptual problems regarding what accounts for observed effects of structural as well as of individual level variables (Baron/Bielby 1980; Sørensen 1982). Most theory in the sociology of labor markets is about the organization of the economy, into dual and other divisions, and not about what models should look like and which mechanisms generate observed outcomes.

The lack of attention to the specification of the mechanisms accounting for observed outcomes and the nature of the dependent variable make sociological attainment research vulnerable to imperialistic forays by economists. The economic nature of the dependent variable is clear with respect to earnings and incomes, that are more and more frequently employed as dependent variables in sociological attainment research. Socioeconomic status is usually not seen as an economic variable. It is a somewhat nebulous concept. Despite the frequent use of "prestige", a relational concept, to denote this variable, Goldthorpe and Hope (1972) have convincingly argued that this it is not. Rather, it seems to refer to a quality of "goodness" of occupational positions. If economics is about the allocation of scarce resources and goods, then socioeconomic status is an economic variable.

That sociological attainment research is research on an economic process to be specified by economic theory is admitted in one of the few explicit statements about the matter presented by Berg (1981). He states that the sociology of labor markets is about the specification of the demand side of labor markets. A similar implication follows from the discussion presented by Grannovetter (1981). This certainly appears to be what most economists believe sociologists are doing.

There is, however, another way to conceive of the matter. The classic sociological idea of seeing the economy as a subsystem should mean sociologists could have something to say about the boundaries for the operation of market mechanisms and about alternative mechanisms for the allocation of valued resources and goods. This will be attempted in this paper. It will be argued that basic sociological concepts and ideas provide the ingredients for the formulation of a theory about non-market allocation mechanisms, of particular relevance for the study of attainment processes. Of course, if all allocation processes are seen as economic, then this theory is also an economic theory. It is, however, a theory about what should happen when markets are only of indirect relevance for allocations. This seems to be a situation quite difficult for standard economic theory to imagine.

The basic ideas derive from Weber's distinction between open and closed relationships presented in Economy and Society $(1956)^{1}$. The distinction will be applied to positions in social structure. Open positions are seen as characterizing competitive markets with the properties assumed in neo-classical economic theory, and the mechanisms that allocate people to positions in such markets are those described by the orthodox theory. The main task of this paper is to specify the allocation mechanisms operating when positions are closed so that market mechanisms cannot operate. The mechanism argued to govern allocations when positions are closed, not freely accessible to outsiders, will be referred to as vacancy competition. I shall try to show that vacancy competition differs importantly from market competition with respect to how observed effects of independent variables on attainments should be interpreted; and, with respect to how variables should be measured.

1 I am indebted to John Myles for first pointing out to me the usefulness of Weber's distinction for the analysis of mobility processes. Our collaboration resulted in Myles \& Sorensen (1975) that points out some of the implications of the distinction between closed and open positions for the analysis of intergenerational mobility. 
The next section will develop more fully the idea of closed and open positions. Then follows a description of the vacancy competition mechanism allocating people to positions in closed position system. Many of the illustrations, in this discussion, will be labor market examples. I then give an explicit treatment of the labor market application of these ideas. It seems useful further to show that the ideas are not specific to this particular area of application. Therefore, I shall illustrate how the ideas of closed positions and vacancy competition also can be used in the analysis of school systems and the educational attainment process.

Several of the ideas presented in this paper are not original to this paper. Some of the characteristics of allocation mechanisms operating in closed position systems have been described by Boudon (1974) and Thurow (1975). The latter's notion of job competition is quite close to the idea of va. cancy competition. The vacancy concept and the idea of vacancy chains defining the opportunity structure of organizations, is due to White (1970). Important ideas about the operation of internal labor markets - the main labor market structure thought to have the property of a closed position system - are due to Doeringer and Piore (1971) and, especially, Williamson (1975). Hirsch's (1976) notion of "positional goods" is also similar to the ideas presented here.

More than has been done previously, this paper emphasizes the importance of the ideas for how empirical research on these ideas is to be conducted. It is ultimately difficult to argue for the importance of suggestive ideas if they do not have operational consequences. A few empirical results are available to illustrate these consequences. These examples are described more fully elsewhere (S $\phi$ rensen 1979; S $\phi r e n s e n /$ Hallinan 1982). Elements of the theoretical development have also been reported on elsewhere (Sørensen 1977; Sфrensen/Kalleberg 1981).

\section{Systems of Closed and Open Positions}

This paper is concerned with mechanisms of access to positions in labor markets and educational structures. These positions should be conceived of as defining tasks and activities for incumbents to carry out. In labor market applica- tions, the positions are jobs. In educational applications, positions are places in instructional groups or classrooms. The labor market application shall be used here in the development of the main arguments. The schooling application necessitates certain modifications and elaborations. This will be described in the context of this application.

Incumbents of positions will be assumed to receive benefits in return for the execution of task and activities of positions. The benefits may be a direct payment for the execution of a specific task; a stream of payments over a period of time in the form of wages; or, the benefit may consist of opportunities for future rewards resulting, for example, from participation in educational activities. Tasks and activities associated with positions, and benefits and rewards obtained as a result of occupying positions, make individuals care about which positions they occupy. They are assumed to have interests and preferences related to the distribution of benefits and the distribution of individuals among positions (in particular themselves).

Thus, the concern here is for hierarchically organized positions where individuals' attainment of unequally distributed rewards and opportunities depend on getting access to positions. The process of access to such positions will be argued to depend on whether positions are open or closed. Weber defines the concepts of open and closed social relationships as follows:

"Eine soziale Beziehung (gleichviel ob Vergemeinschaftung oder Vergesellschaftung) soll nach außen "offen" heißen, wenn und insoweit die Teilnahme an dem an ihrem Sinngehalt orientierten gegenseitigen sozialen Handeln, welches sie konstituiert, nach ihren geltenden Ordnungen niemand verwehrt wird, der dazu tatsächlich in der Lage und geneigt ist. Dagegen nach außen ,geschlossen“ dann, insoweit und in dem Grade, als ihr Sinngehalt oder ihre geltenden Ordnungen die Teilnahme ausschließen oder beschränken oder an Bedingungen knüpfen" (Weber 1956: 23).

Weber goes on to argue that competitive markets are characterized by open relationships, while the establishment of the worker's right to and possession of particular jobs is an example of a closed relationship. The characterization of market relationships as open and of closed relationship as involving control over access to positions is basic for the arguments to be developed here. 
Weber speaks of closed and open relationships. Here the terms open and closed will be applied to positions. There is no change in meaning implied. Positions are nodes in social relationships and are defined by these relationships. Closed and open positions thus refer to the ease of access to the basic relationship defining the position. In labor market applications this means access to the employment relationship.

The distinction between open and closed positions or relationships will be used here in a more specific sense than provided by Weber. Positions will be referred to as closed when they are available only when vacated by the previous incumbent. This means that in closed position systems new allocations can only take place when positions become vacant so that the timing of allocation is governed by the tim. ing of the occurrence of vacancies. In contrast, incumbents of positions in open positions systems can be replaced at any moment in time and the occurrence of vacancies is irrelevant for the timing of new allocations.

The causes of the emergence of closed position systems will be elaborated in the context of specific applications. Here, certain general properties of such systems shall be noted because of their relevance for the allocation process. Three such properties are of particular relevance: (1) the predetermined and well specified nature of positions in closed position systems; (2) the indefinite duration of matches between people and positions when positions are closed; and (3) allocations to closed position systems that represent the outcomes of authority decisions rather than market exchanges.

The predetermined and well specified nature of positions in closed position systems means that such systems have "more structure" than open position systems. In labor market systems this results from interdependencies among jobs in a division of labor, from the existence of training ladders and on-the-job training arrangements, from the existence of promotion ladders, and from the nature of such systems as hierarchically organized authority systems. Some of these features are linked to the causes of the positions being closed (on-the-job training arrangements), others may be seen as consequences of closed position systems (promotion ladders). Regardless, these features of closed position systems mean that relationships among positions are so well established that positions come to exist independently of people. In Simmel's apt formulation from his discussion of super- and subordination or authority relationships:

"Arbeitsteilung aber steht überall in Wechselbeziehung mit der Objektivierung des Handelns und der Verhältnisse ... Das Apriori der Beziehung sind jetzt nicht mehr die Menschen mit ihren Eigenschaften, aus denen die soziale Relation entsteht, sondern diese Relationen als objektive Formen, „Stellungen“, gleichsam leere Räume und Umrisse, die erst von Individuen ,ausgefüllt" werden sollen" (Simmel 1908: 236).

Simmel goes on to discuss a main issue for this paper: "The inevitable disproportionate distribution of qualifications and positions" (Simmel 1908: 243).

It is the predetermined and well specified nature of positions in closed position systems that makes it meaningful to speak of vacant positions in such systems to be filled. It should further be noted that the linkages among positions in closed position systems imply that it in general is impossible to adjust the number of positions in a fluid manner to cycles in product markets (or funding levels) or to changes in the supply of candidates for positions. The existence of a single position is linked to the existence of other positions so that single positions usually cannot be created or eliminated at will.

It follows from the definition of closed positions that the duration of matches in a closed position system will reflect that no one can get access to a position unless there is a vacancy. In closed position labor market systems new allocations only can be made when the previous incumbent has left voluntarily. Unless the incumbent is forced to retire, voluntary departures only should be made for a better position. In closed position systems, duration of matches will therefore be governed by upward mobility regimes or promotion systems. It will be shown in the next section, that these mobility regimes are organizationally and historically specific. The timing of new allocations is generally not under the control of the authority (employer) who makes the allocation. This has two important consequences. First, new matches usually cannot be established when changes in individual performances, or the availability of a candidate with qualifications believed to be superior to an incumbent, would make it desirable. Second, when a new match is estab- 
lished, there is considerable uncertainty about how long it will last.

The indefinite duration of matches in closed position systems, and the constraints on the creation of new positions, combine to produce only a limited number of vacancies in a system at any moment of time. Also, a limited and usually well defined set of candidates will exist for these vacancies as a result of the supervisory, technical, incentive and learning relations that exist among positions. The authority decisions that establishes matches between individuals and positions in closed position systems, are thus single decisions involving the choice between a limited set of candidates in a particular system.

Open position systems, being markets, form polar opposites to closed position systems on the attributes described above. Specifically: (1) open position systems lack "structure", i.e. positions cannot be said to exist independently of incumbents; (2) the duration of matches in open position systems is short and definite; and (3) matches are established in market exchanges rather than as a result of authority decisions.

Open position labor markets are like markets for other goods. Buyers, who are employers, offer wages for the execution of specific tasks and activities. Sellers, who are workers, decide how much leisure time they are willing to give up at the going wage rate in order to perform tasks for employers. This results in schedules of work demanded at given wage rates and work supplied at given rates. The intersection of these two schedules establishes a market wage rate or price for the particular type of work transacted for. The conception of labor market that is implied by this application of standard price theory is one where transactions result in employment contracts that are like sale contracts for ordinary goods (cf. Simon 1957). Employments are established for the (brief) periods of time it takes to complete specific tasks. New tasks produces new transactions or employment contracts. In other words, matches between individuals and tasks are reestablished continuously. Positions, conceived of as sequences of tasks are open because new contracts, available to anyone, will be established for each new task in the sequence of tasks.
In labor markets that conform to this conception, the separation of individuals and positions is of little relevance. The number of positions is the amount of work demanded at given wage levels. In a labor market in equilibrium no more work will be demanded at the given wage and it makes little sense to speak of vacant positions. The level of employment and hence the number of positions respond in a fluid manner to chances in the market. Positions are assumed to be unrelated to each other, or "unstructured".

Market transactions result in matches of individuals to well specified tasks. New matches are established when tasks are completed, and these new matches need not involve the same persons. Durations of matches are therefore short and definite. There is no uncertainty about how the task is to be carried out and no need to be able to predict future performance since the match is of short duration. Or can be made of short duration without adverse consequences.

The market transactions that allocate people to positions in open position systems are exchange relations rather than authority decisions as in closed position systems. In the neo-classical economic conception of labor markets, a very large number of such transactions are assumed to occur simultaneously and independently of each other. They establish market prices or wage rates for different types of labor, and no one is prevented from working at some wage rate. No single transaction will influence these wage rates. Employers can rely on competition among workers to minimize labor costs and workers can rely on competition among employers to ensure they get the market wage. While they cannot influence that market wage, they can increase their earnings by working more or by supplying a different and higher quality type of work.

Open and closed positions are end points on a continuum. No labor market is completely open. There is involuntary unemployment. No labor market structure is completely closed, either. Dismissals do take place and they sometimes are carried out because a candidate with better qualifications than the incumbent is available. Nevertheless, it is the contrast that matters for the nature of the allocation process. For the open position system scenario, this allocation process is well described in standard economic theory. 
The mechanisms that govern allocations in closed position systems will be described in the next section.

Those who apply the open position market assumption to labor markets are likely to argue against the importance of the distinction made here. They would claim closed position systems are short term imperfections; that the arguments presented here ignore the role of competition; and, in the long run, competition will eliminate whatever implications are drawn from the nature of closed positions. Two comments are in order. First, it is unreasonable to see competition as a monopoly of markets. In fact, a great believer in markets, Hayek, has argued that if markets completely conform to what is assumed in classical economic theory, there would be no competition in the sense of the definition of competition provided by Samuel Johnson, "the action of endeavouring to gain what another endeavours to gain at the same time" (Hayek 1948: 96). Complete information, uniform and well specified goods, and the rest would make this action quite unfeasible.

Competition for access to positions in a closed position system can indeed be ferocious; one only has to ask French students. About the long run, the argument here is that the distinction between open and closed positions determines the structure of the processes allocating people to positions. Once determined, it is difficult, if not impossible, to imagine why basic mechanisms would change from one form to another with the passing of long time.

Second, it is not the argument here that competition in product markets does not exist, or that firms could not behave as they are supposed to with respect to equating the marginal productivity of some aggregate of their labor force to the wage bill. Of interest is the internal pricing and allocation of labor, for this is observed in research on the socioeconomic attainment process.

\section{Vacancy Competition: Mobility Regimes and Queues}

The indefinite duration of matches in closed position systems and the limited number of va- cancies and candidates for vacancies appearing in any moment of time are of fundamental importance for the nature of the allocation process that emerges in closed position systems. These attributes imply that occurrences of new allocations, created by vacancies, are governed by mobility regimes in systems of closed positions; and that outcomes of allocations will be determined by rankings of candidates, who, for this reason, may be seen as forming queues for the opportunities presented by vacancies.

New vacancies are created when people leave the system or when new positions are added to the system or organization. New vacancies may set in motion vacancy chains (White 1970). When a new vacancy is created, either a person from outside of the system fills the vacancy, or a person from within the system moves, or is moved, into the vacancy. The latter creates a new vacancy. Again, it may be filled from the outside or from within. Vacancies filled from within may either be filled by a person at the same level or from the level below. In the latter case a promotion occurs. In a hierarchically organized system, the filling of vacancies from within the system may be conceptualized as a process where a vacancy moves down as a person moves up. The chains thus formed are then vacancy chains moving in opposite direction of promotions, to be terminated by someone entering from the outside, or by a position being eliminated.

The rate at which new vacancies are created, by people leaving the system or by new positions being added, together with the distribution of positions determines how many vacancies are created in a period of time. This quantity, and its distribution, forms the opportunity structure of the system; i.e., in Simmel's terms, how many empty spaces are to be filled at the various levels. There are two important aspects of this conception of opportunity structure.

First, as already noted, the timing of the creation of vacancies has nothing to do with the performances and qualifications of the candidates for these vacant positions, or with whatever changes take place in qualifications and performances. One may work hard for a promotion and not get it, because there are no promotions to be gotten. One may also work not so hard and 
still get a promotion because one was at the right place at the right time. In open position market systems one can freely move to whoever offers one more for one's additional qualifications; and one should do so to get the benefits of market competition. In open position systems, life cycle changes in socioeconomic outcomes reflect additions to one's productivity. In closed position system, life cycle changes in socioeconomic outcomes may come about without any changes in performance, skills, or knowledge.

Second, the opportunity structure in a closed system reflects the past history of the system or organization to which one belongs. People do not leave closed position systems randomly in time, but tend to leave in certain age intervals (for retirement). Growth in the number of positions follows cycles in product markets or in funding levels (for public bureaucracies). This will strongly influence the rate at which vacancies are created and induce accidental differences in the age distributions at various job levels. The organizational and historical specificity of the opportunity structure again contrasts to the situation in open position systems, where turnover is independent of past business cycles. A person's attainments, in market systems, in no manner depends on what happened to his/her employer in the past or on the composition of the particular labor force of the employer.

Characterizing the opportunity structure is difficult in concrete empirical systems. Information on vacancies is often not available; the impact of history and the organization of positions may be difficult to specify. A considerable amount of work has been done, however, on the mobility regimes of organizations (see for example, Bartholomew 1973), particularly in the area of manpower and educational planning ${ }^{2}$. Using strong and simplifying assumptions, it is possible to characterize the opportunity structure by a single parameter. This will be described in the next section.

Specifying the mobility regime does not inform about who will be the one to take advantage of

2 It is interesting to note that most of this work has been carried out in Europe where the idea of everything being markets is less widespread. the promotion opportunity. The simple, but important, answer is: it depends on the set of candidates. Because of the indefinite or arbitrary duration of matches there is considerable uncertainty about future performance. This uncertainty is reduced by relying on past performance, which is one reason why vacancies tend to be filled from within rather than from the outside. The decision by the authority performing the allocation has the objective of finding, among those available, the most qualified candidate for the vacant position (in labor markets, unions may interfere in this by insisting on seniority principles). Therefore, a ranking is performed of the available candidates and the position allocated to whoever ranks first.

Performing a ranking may seem an innocuous operation. But, the use of rankings have important substantive and methodological implications. Rankings have no metrics for the distances between ranks and provide no information on these distance. A person may work hard to change his qualifications and performance. The effort may not change his rank order, because the unmeasureable distance to the next in the queue was too great (or because the decision maker used a weighting schema that did not give enough weight to the particular performance displayed). Rankings also imply that the outcomes of people's efforts become interdependent. Thus, the efforts of other candidates becomes a very important consideration. Displaying a lot of effort to obtain a promotion provides a strong incentive to others to increase their efforts too, in order to maintain the rank orders. This is a reason why promotion systems are to be conceived of as incentive devices. But, for this very reason, there can also be an incentive to convince others to reduce effort. Rankings bear no relation to overall effort levels. The same outcomes in terms of career changes may come about at very low effort levels and at very high effort levels. This does not affect the outcome of the allocation process, and presumably this is what matters to individuals; but it does affect the performance of the organization. The strategic behaviors toward reducing efforts by some collective, though informal, agreement may be more serious the more stable the group of candidates. The stability of the group depends on the rate of pro. motion. One way to increase this rate, since little can be done about the creation of vacan- 
cies by people leaving the system, is to increase the number of job levels. Promotion systems therefore become more elaborate than dictated by technical considerations or chains of commands.

\section{Allocation decisions are authority decisions} about whom to select for a particular vacancy among a small group of candidates. These decisions therefore pose a "small numbers problem" (Williamson 1975). The candidates will present themselves in their best light, and, in fact, have incentives to present themselves in a better light than reality may justify. Such opportunistic incentives are checked in market transactions, because of the large number of transactions and the short duration of each match. In closed position systems there are no similar checks. One result should be heavy reliance on "objective" characteristics, such as educational credentials, and visible attributes, such as race and sex, believed to provide information about future performance (the latter is the source of what has been labelled statistical discrimination by Thurow (1975): a group attribute is believed to provide information on individual members of the group). There is, in other words, a potential for inequality of opportunity and discrimination inherent in the allocation of people to vacancies in closed position systems, not present in open position markets - where competition eliminates discrimination (Becker 1971).

The small numbers problem presents less of a problem with internal promotions, and it is therefore argued by Williamson to be one cause of the emergence of closed position internal labor markets. With hirings from the outside the problem does become relevant. It is possible that some systems can rely on market competition in entry positions; this is widely believed to take place in internal labor markets (Doeringer/Piore 1971). But for certain organizations this may not be feasible. If new positions are added, recruits from the outside may be needed also at higher job levels.

Rank orders are irrelevant in open position systems and small number opportunism checked, as noted, by the market. The market provides a price system for individual attributes in an interval level metric, that is money. And, the ef- forts of one can be changed independently of the efforts of others, because outcomes are established in independent transactions.

The use of rankings in vacancy competition has important methodological implications. The measurement strategies employed in research on the attainment process should reflect the mechanisms and procedures govering allocation processes. Conventionally used metrics are not informed by a conception of the allocation process in closed position systems - for example, education measured in years of schooling. Empirical examples of the usefulness of this insight shall be provided later.

Simmel's problem, the inevitable disproportion between the distribution of qualifications and the distribution of positions, is solved by the use of rankings: they may be fitted to any outcome distribution. This use of rankings also resolves a classic problem in the study of income distributions dating back at least to Pigou (1932): how can the well known skew in the income distribution be compatible with the presumed normality of the ability distribution ${ }^{3}$. If incomes are allocated according to vacancy competition, the problem ceases to exist, for the ability distribution is used without interval metrics.

Simmel points to another solution. One may not even specify the qualifications of the position, but assume the position makes the man. "Whoever God gives an office, he also gives the mind necessary for it". This proverbial piece of optimism about the human fate is, in fact, the rationale for internal labor markets provided by Thurow (1975), though the minds are here created by the training on-the-job. It is a good rationale for promotion by seniority. According to Simmel, this solution reaches its ultimate form in the Catholic clergy. Here the consecration creates the special qualifications for the positions to which it calls the individual.

3 One solution to the problem is to argue that ability is not normally distributed, only observed in a metric producing a normal distribution. Mincer (1970) resolves the paradox using human capital theory, keeping the assumption of normally distributed abilities. 
The use of rankings, and in some cases, perhaps, consecrations, to fill vacancies created by idiosyncratic mobility regimes, are then the main features of vacancy competition. System size may be seen as a variable that, to some extent, interacts with the vacancy competition mechanisms. In large systems, vacancies may be more predictable and occur at a more frequent rate. The number of candidates for these vacancies is larger. As a result, the number of allocations to be performed is larger. Therefore, it is conceiveable that, in large systems, the predictions from market mechanisms corresponds more closely to predictions from vacancy competition. The importance of this qualification should not be exaggerated. Large systems are often aggregates of smaller systems. The next section will describe empirical results obtained from an analysis of vacancy competition in national labor markets.

\section{Vacancy Competition in Labor Markets}

There are long standing disagreements on the nature of labor markets and the appropriateness of applying the open position conception to labor markets. Already Mill (1900) argued against labor markets being completely homogenous and open and pointed to the importance of "non competing" groups presenting barriers to entry into certain pursuits, for example occupational groups. In fact, the empirical existence of such imperfections was already suggested by Adam Smith. Institutional economists dominated labor economics until the fifties and were much occupied by the structuration of labor markets (e.g. Dunlop 1957; Kerr 1950). They lost their dominant position in the sixties to neoclassical economics, particularly human capital theory. This meant a return to the conception of labor markets as open and homogeneous. This, in turn, has inspired much reaction from neo-institutionalist and radical economists and later from sociologists of the labor market (for a review see Kalleberg/S $\phi r e n s e n ~ 1974$; an important citique of the reaction is provided by Cain 1976).

Much of the critique of neoclassical labor economics has been directed at the assumption of market homogeneity. A mere barrier to entry is nevertheless not so very interesting. It may only establish different supply and demand schedules inside and outside the barrier. This does not, by itself, mean that market mechanisms do not account for the attainment process. Market mechanisms need open positions behind barriers. This is, of course, quite possible. When barriers are to closed position structures, the arguments of this paper become relevant. Closed position systems are described in the considerable literature on internal labor markets. This literature suggests the causes of closed position systems in labor markets. Of particular relevance are Doerringer and Piore (1971), Williamson (1975), and Thurow (1975).

\section{The causes of closed labor market positions}

Williamson (1975) considers the difficulty of establishing market contracts for the employment relationship in jobs that are idiosyncratic in nature. He sees this difficulty to be the caise of the emergence of internal labor markets. Idiosyncratic jobs are those where most of the skills and knowledge needed to perform a job are aquired on the job. Further, a non trivial amount of uncertainty and complexity characterize these tasks. The uncertainty and complexity makes standards sales contracts for employment impossible (see also Simon 1957). Therefore, the essential feature of open position systems of many, independent and short duration transactions will not obtain. Combined with the opportunities for opportunism provided by the employee's special skills and knowledge, individual level contracts are unenforceable. The result is collective employment relationships that are authority relations. Wages are attached to jobs and not to individuals.

The absence of individual wage bargaining in internal labor markets poses an incentive problem. Supervision is costly and has limits because of information problems. As already suggested, the result is the establishment of promotion structures as incentive devices. The use of promotion systems as motivational devices has also been much emphasized by Stinchcombe (1974). The idea, in fact, goes back to Weber's analysis of bureaucracy.

The link between jobs for which needed skills and knowledge are acquired on the job, and internal labor markets, where employees have 
a great deal of job security, has been argued by several. In fact, the classic formulation of human capital theory by Becker (1964) sees specific on-the-job training as having the effects that individuals will not be payed the competitive market wage and that employers (who have to pay for specific training that cannot be used elsewhere) have an incentive to retain the employee as long as possible to obtain the most return on the costs of specific on-the-job training. A more extreme formulation is provided by Thurow (1975) who conceives of practically all skills to be created in jobs, so that internal labor markets form a system of consecration. This implies that it becomes impossible to make a distinction between individuals and jobs (for reasons opposite to those in open position systems). Thurow also emphasizes the need for job security or closed positions to induce trainers to train the trainees in on-the-job training ladders. A broader formulation, also stressing interdependence of jobs and the importance of collective action for closed employment relations, is provided by Sbrensen and Kalleberg (1981). Whatever the formulation, there is substantial agreement that certain job structures generate matches of people to jobs dissolved usually only on the initiative of the employee (except for mandatory retirements).

The role of promotion systems as incentive devices reinforces the closed nature of jobs in internal labor markets. For promotions to provide incentives there should be a chance for everyone to obtain them. This is not the case where there is a high frequency of involuntary dismissals or other attempts by the employer to take advantage of market changes in the qualifications of candidates. Non-individual wage bargaining is also reinforced by promotion systems. If those at the same level in the promotion hierarchy do not obtain approximately the same job rewards, the incentive of promotions is diffused.

The closed nature of jobs does not prevent business cycles in product markets from making it necessary to curtail production. In firms, that can be assumed to have closed position internal labor markets, it is telling that unemployment typically takes the form of lay-offs, where the individual usually retains the right to the job. Further, lay-offs, when they occur, are by seniority.
Doeringer and Piore (1971) link the existence of internal labor markets to labor market segmentation. The so called primary labor market consists of internal labor markets, while secondary markets are conceived of as open position competitive markets. This dualism of labor markets has been much cited by sociologists, but it is usually linked then to dual economy ideas (Hodson 1978; Beck et al. 1978), and earnings models are used that do not mirror internal labor market mechanisms. It is of relevance for the specification of the vacancy competition model, to be described next, that the secondary market usually is considered a low attainment market, while the primary market, consisting of a set of internal markets, is associated with differentiated, including high levels of attainments. In other words, most of the variation in attainments is produced by internal labor markets, hence by vacancy competition.

It should be noted, finally, that internal labor markets provide efficiency gains. This point is much stressed by Williamson, 1975 (and Weber). They are thus sustained and reinforced by competition in product markets and not aberrations, as some seem to believe.

\section{A specification of vacancy competition in labor markets}

A main problem is how one would obtain evidence to support the idea of different mechanisms working in internal and competitive labor markets. Neoclassical labor economists have not been unimaginative about reinterpreting evidence brought in support of scenarios alternative to the open labor market model; or they have been able to point to methodological problems with the evidence for alternative scenarios (Cain 1976). This partly reflects that very little has been done to operationalize ideas about allocation mechanisms in internal labor markets. Relying on earlier work (Sфrensen 1977, 1979), a specification of the vacancy competition model and some empirical support for this specification will now be presented.

The standard of comparison is, of course, human capital theory. It assumes open position systems and obtains impressive support for some of its predictions. Human capital theory is about schooling and training decisions. These decisions 
are conceived of as investment decisions. Their outcomes depend on the earnings return the market provides to additional training and schooling. Market returns are assumed to be cal culated from life time earnings streams and this provides a link between the amount of human capital and the earnings of individuals ${ }^{4}$. The theory only accounts for the supply side of the supply and demand mechanisms that determine wages in open position markets: the predictive power of human capital models depends on the degree to which markets are homogeneous, which is why so much attention has been devoted to this issue.

A major empirical study of the earnings attainment process, informed by human capital theory, is presented by Mincer (1974). Using crosssectional Census data, Mincer accounts for a substantial amount of variance in earnings (56\%) using only three variables. This is as much, or more, variance explained as in sociological earnings models using a large number of "structural" variables in addition to numerous individual attributes. One of these variables, weeks worked, primarily represents an accounting relation (it is an important one as the theory relies on market theory of prices or wage-rates; this accounting relation is nevertheless ignored in much sociological research critical of human capital research). The other two variables are education and experience. Human capital theory is usually seen to be about education. Its relationship to earnings is assumed to reflect the aquisition of skills in schools. The market returns to these skills should cover the costs of acquiring them, for anyone doing so. A major portion of the costs are earnings foregone by staying in school. These costs are roughly proportional to numbers of years spent in schools. Therefore, measuring educational attainments in years of schooling provides an appropriate metric.

4 There are strong assumptions involved in the derivation of the human capital earnings model employed by Mincer (1974) and many others. It is assumed life time earnings are equal for everyone regardless of educational attainments, as all current earnings differences compensate for training costs differences. Without this assumption the earnings equation is not identified and coefficients to education do not measure rates of return (Rosen 1976).
Education actually accounts for only a modest portion of the variance explained in earnings. Experience is much more important, using the somewhat ambiguous criterion of variance explained. Experience accounts for earnings variation, according to human capital theory, because it represents additional skills and knowledge aquired on the job (and transferable to other jobs so that individuals have to pay the costs of training themselves). Because of finite lifetimes in the labor force, and because investments become more costly as earnings increase, the rate of investment will be highest in the younger years and gradually taper off. Earnings should therefore show the same non-linear growth by time in the labor force, and do so, though vacancy competition also can account for this. It is important to note that in human capital theory, experience reflects changes in individuals that can be observed in the crosssection as the process is assumed to be in equilibrium.

A specification of the vacancy competition model should capture such empirical observations and hopefully provide some new insights into the process. The specification described in Sфrensen (1977) relies on strong, but not com. pletely unrealistic, assumptions. One such assumption is that attainment levels are exponentially distributed. This is an assumption about the distribution of empty spaces or positions, not about individuals. Nevertheless, the distributions of individuals corresponds roughly to the distribution of positions, as most positions are filled. In a discrete variable representation of attainment levels, the exponential distribution corresponds to the geometric distribution, often assumed to describe hierarchical structures where there is a fixed ratio of super-to subordinates.

If $y$ denotes the attainment level, the distribution of jobs thus can be characterized by the distribution function $F(y)=1-e^{\beta y}$ where $\beta$ is assumed to be negative. The parameter governs the shape of the pyramid. The larger $\beta$ is in absolute magnitude, the fewer positions will exist at higher levels of attainments. In this distribution, vacancies are assumed to be created at all levels and at a constant rate by people leaving the system. The rate at which vacancies are created is characterized by a parameter, $h$. 
Vacancies not immediately filled from the outside set in motion vacancy chains providing opportunities for upward moves to people in the system. Positions are assumed to be closed and downward moves to be infrequent and to be ignored. The exponential distribution and the assumption of a constant rate result in a very simple mobility regime. It can be derived that, at each level, vacancies will arrive at a constant rate, $q$, where $q$ further can be shown to be $q=-h / \beta$. The quantity $q$ thus represents the opportunities for gains in attainments, or promotions, present at each level. It is determined by the shape of the distribution (governed by $\beta$ ). and the rate at which new vacancy chains are created (governed by h).

People are not equally likely to take advantage of the mobility or promotion opportunities present at their level. They have qualifications taken into account in promotion decisions. Assuming these qualifications do not change over time after entry into the labor force (in sharp contrast to human capital theory), the proability of a discrepancy between a person's current level of attainment and these qualifications should be highest at the start of the career. For all individuals at a given attainment level, individual rates of getting promoted should sum to the overall rate at that level, $q$. If this rate is denoted $r(t)$, then

$\int_{0}^{\infty} r(t) d t=a$

A simple specification of $r(t)$ that will solve this integral equation for the individual rate is:

$r(t)=e^{b t}$

where $t$ is time since entry into the labor force, or experience as conventionally measured. The parameter $b$ is equal to $\beta / h$ and measures the magnitude of opportunities for gains in attainments provided by the system. The smaller $b$ is in absolute magnitude, the more opportunities for gains the system provides. In empirical research using these ideas, major attention is focused on this interpretation of $b$.

Moves to higher levels are jobs shifts and the number of shifts in a period of time can be derived by integration of (1). A person will start with a certain level of attainment y (0). By time $t$ his/her attainment can be shown to be: $y(t)=\frac{z}{b}\left(e^{b t}-1\right)+e^{b t} y(0), b<0$

Here $z$ is a measure of a person's resources or qualifications, as determined, for example, by educational credentials. This attainment model has some of the same features, though not the same functional form, as Mincer's human capital model. The human capital model does not include y (0) since it assumes the earnings attainment process is in equilibrium at all times. Both models provide the same general prediction about the shape of the attainment curve by time in the labor force. It is non-linear, rapidly growing in the early years and then gradually tapering off.

Since the human capital theory assumes equilibrium, it can be estimated from cross-sectional data. The parameters of (2) cannot be identified unless data on change in attainments are used. Equilibrium attainments, which will be maximum attainments because of the absence of downward mobility, can be obtained by letting $t \rightarrow \infty$. This produces:

$y(e)=\frac{z}{b}$

This expression can be made to look like a convential attainment model by expanding $z$ linearly in measures of individual attributes, so that $y(e)=-T_{h}\left(c_{o}+\Sigma c_{i} x_{i}\right)$. The ratio $c_{i} / b$ is estimated as coefficients with such an additive model, assuming the process is in equilibrium. The observed effects of independent variables thus confound the contribution of individual attributes to a person's overall level of resources and the number of opportunities determined by $b$.

\section{Empirical results}

Information about the usefulness of the vacancy competition model in this specification is not obtained by observing education having an effect on attainments, or by demonstrating the shape of the life cycle attainment profile. These features could as well be explained by human capital theory. More information is provided by obtaining evidence for the validity of the interpretation of parameters; the explanatory power of the model; and the implications of the vacancy competition theory fo metrics of variables. 
The mathematical specification of the vacancy competition model assumes an exponential distribution of attainments. Socioeconomic status can be seen as a comprehensive measure of the rewards provided by positions in social structure. It has, as usually measured, an ordinal metric (though it also usually is treated as an interval level variable). The assumption about the exponential distribution can easily be implemented. Nothing prevents assigning a metric to socioeconomic status that generates this distribution, as long as this metric preserves rank order. This provides a metric, called SAS; its derivation is described in Sфrensen (1979).

The distributional assumption is of course not essential for the conception of vacancy competition, though it is essential for the mathematical specification. The conception of vacancy competition implies that attributes of individuals used in the allocation to vacant positions are used to form rankings; thus, only ordinal metrics are implied for these variables. The mathematical specification does, however, need a measure with a stronger metric. One may assign these variables a metric reflecting the outcome distribution, that is the exponential distribution, provided the metric preserves rank orders.

In the vacancy model, education should be considered a key individual attribute in the allocation of people to closed positions. The measurement of education in years of schooling has a justification only in human capital theory. In vacancy competition education only establishes rank orders.

There has been a dramatic secular change in educational attainments in recent history. This means, the rank order, or competitive advantage, provided by a given level of educational attain. ment, say high school, has declined. This can be captured by standardizing the educational distribution by cohorts of entrants into the labor markets. Using this strategy, and imposing the exponential distribution on the educational attainment distribution for each (five year) cohort, results in a metric for education, called EDR (Sфrensen 1979). This metric measures competitive advantage, assuming most people compete with those who enter the labor force at roughly the same time (these' are not cohorts of people born in the same period because of the consider- able differentials in school leaving ages). The metric assigns higher values, say, to high school education for those who entered years ago and compete with others with lower levels of education, than it would assign to high school in more recent cohorts.

In these new metrics the correlation between education (EDR) and socio-economic status (SAS) is .625 for a very large sample of white males, aged 20-64 in 1970 (Sфrensen 1979) ${ }^{5}$. In the conventional metrics of Duncan's SEI and years of schooling, the correlation is .552 . It should be noted this correlation, assuming a linear relation, is a misspecification of the vacancy competition model. It assumes the process to be in equilibrium, presumably not the case for the youngest age groups. Still the difference is noteworthy in favor of the vacancy competition model; most of the difference is due to the treatment of education: the correlation between EDR and SEI is .600 .

A conventional status attainment model with only two variables, education and experience, produces results consistent with the zero order correlations. The $\mathrm{R}^{2} \mathrm{~s}$ in the new metrics are .394 as opposed to .328 in the conventional metrics. The $R^{2} s$ are higher than any reported in the status attainment literature for models that include measures of family background. These models do not include experience. In Sфrensen (1979) both a linear and a squared term for experience are included in models in both metrics, and experience has a substantial effect. Still, the metrics provided by the vacancy competitions model produce a larger $R^{2}$ than obtained in a status attainment model that includes age and age squared (Bielby et al. 1977).

It may be argued that at the outset it was said the standard of comparison would be human capital models in earnings. Cross-sectional earnings models have not been estimated using the vacancy competition model, and, in

5 The sample used in Sфrensen (1979) is obtained from the Public Use Sample of the 9870 U.S. Census. From the one-in-a-hundred P.U.S. file samples of white males, white females, black males and black females were obtained. Sample sizes varied from 18,000 to 30,000 . 
any event, the use of the vacancy competition model as specified in (2) would be a misspecification on data like those used by Mincer (1974). Nevertheless, the status and earnings attainment models are structurally equivalent, even though status attainment research cannot be said to be informed by human capital theory. The relation between education and socioeconomic status, seen as a measure of the "goodness" of jobs, should be explainable by human capital theory if it explains attainment processes, with education measured in years of schooling.

\section{Performance, measured by $R^{2} s$, is dependent} on population variances and measurement reliabilities. A more informative test of the usefulness of the vacancy competition model would be obtained by direct estimation of the parameter $b$ assumed to measure the number of opportunities in closed position systems. Using information on change in attainments, 19651970 , such estimates are presented in Sфrensen (1979) for national samples of population groups defined by sex and race. Racial and sexual inequalities are widely believed to reflect differences in opportunities. This, therefore, provides a way of validating the interpretation of $b$.

The predicted differences come about. For white males $b$ is estimated to be -.222 ; for white women $b=-.264$; for black males $b=$ .282 ; and for black females $b=-.324$. Interestingly, the opportunity structure for black women seems the most unfavorable of all, even though they have average levels of attainments higher than those for black males. The reason for the discrepancy is that black females have higher levels of education than males. Their higher resources thus compensate for their less favorable opportunities.

These estimates pertain again to status attainment. For earnings, direct estimates of $b$ are presented by Rosenfeld (1980). She finds the same differences among racial and sexual groups as those reportes here. She does not find the same picture for status attainment, but she does not use the appropriate metrics for status.

Direct estimates of rates of job mobility provides another way of obtaining empirical support for the model. Such work is reported in


coming, a). The same impact of change in metrics has been established for analysis of rates of upwards shifts in status as measured by the fit of the continuous time stochastic process model used in the analysis of job shifts (Sфrensen, Forthcoming, a).

Of particular interest are the results obtained in the research on job shifts regarding the role of experience. In human capital models, experience measures skills. In the vacancy competition model experience is simply amount of exposure to mobility or promotion processes. No change in performance is implied. Job shifts can be seen as generated by the discrepancy between the current level of attainment and the resources of a person determining the ultimate level (given the opportunity structure). In vacancy competition, time in the labor force is an indicator of the magnitude of this discrepancy. Hence, with the proper specification of the effect of current job rewards and individual resources on the rate of shift, experiences should have no effect. This is indeed observed (S $\phi$ rensen/Tuma 1981) when models where only experience is included (that are like equation (1) here) are compared to models including measures of current rewards and resources.

Overall, there seems to be some support for the vacancy competition model in labor markets. But, the illustrations all pertain to national labor markets. Though this can be justified as focusing on the aggregation of internal labor markets, the historical and organizational specificity of mobility regimes is lost. Other research on organizational mobility suggest the importance of this, see for example Konda and Stewman (1980) and, especially, Rosenbaum (1979) who shows the importance for career trajectories of growth and decline periods of organizations.

\section{Vacancy Competition in School Systems}

There are strong similarities between the educational attainment process, conceived of as a flow among closed positions in educational structures, and the socioeconomic attainment process, conceived of as a flow among closed positions in labor market structures. 
The conception of educational systems as structures of closed positions is not common in sociological research on the educational attainment process. The notion of schools as hierarchies of instructional groups is usually not made explicit, either. These ideas shall first be specified.

\section{Schools as hierarchical educational structures}

The conception of a school as a structure sees instructional groupings as the elements or positions of the structure. The empty spaces, to be filled, are places in these instructional groups as they appear when groups are formed or reorganized. Grouping of students is a universal feature of formal schooling. All school systems use some form of classroom grouping, at least, in the form of age grading. But there are numerous other grouping systems in existence over and above classroom groupings and age grades. If a group of students assigned to a curricular unit is seen as the basic unit in educational systems, these units may be organized in a number of ways. The may be organized to form tracks or programs in US-high schools, or to form separate schooling systems in traditional European systems. Within classroom groupings may be performed with some differentiation among groups in curricula. Such ability grouping will provide the empirical example of the allocation process in schools, described below.

Grouping of students for instructional purposes forms a structure. Two types of relations can be defined among instructional groups. One type is curriculum relations linking instructional groups together, as it is deemed necessary to cover some material before some other material (e.g. in a sequence of mathematics); or, because different parts of a curriculum should be taught in specific combinations to implement the general goals of the school. The other form of relation existing among instructional groups is the relation of a flow of students created by movements of students in definite patterns among curricular units. These flows often reflect curriculum relationships.

The relations defining the educational structure in this manner, are temporal relations. It appears, therefore, educational structures differ from labor market structures, where static relations, such as relations of authority, usually are emphasized. Nevertheless, labor market structures could also be described as mobility patterns that are promotion schedules. The static relations existing among positions in labor market structures do, however, usually identify the hierarchical nature of such systems. The hierarchical nature of educational structures defined by temporal relations needs to be defined.

One may describe flows of students in an educational structure in a matrix similar to a population matrix. Rows and columns in this matrix would be instructional groups identified by listings of classrooms, ability groups within classrooms, tracks, or courses at higher educational levels. One row would denote the "outside" of the school system that eventually absorbs the process. The elements of the matrix would be quantities $a_{i j}$ 's measuring probabilities of students moving from one group to another in the period of time that defines the minimum life time of an instructional group (an academic year or a semester). Using well known results from the mathematical theory of absorbing Markov Chains (e.g. Kemeny/Snell 1960), one may, from such matrices, define a fundamental matrix $(I-A)^{-1}$, where $A$ is the matrix of $a_{i j}$ 's and $I$ is the identity matrix. This matrix reveals a number of properties of the system. In particular, it can be used to calculate quantities technically referred to as expected time to absorption, or, in this application, the number of years to school leaving. Such quantities, cij's, can be defined for any instructional group and would, for each group, reveal the career consequences of being assigned to that group. In principle this could be done for all instructional groups in a school system (for a simple example, see Sфrensen, Forthcoming, b). Since the educational attainment level is so heavily dependent on time spent in the system, the $c_{i j}$ 's measure the educational ranks of ins: tructional groups. Thus, they provide a metric for assigning a vertical dimension to the educational structure.

For many instructional groups such elaborate procedures are not needed. In ability grouping, it is usually clear what is up and what is down. High school tracks, such as college preparatory 
programs, leave little doubt about their intended career implications. There are, however, grouping systems where the career assignments are not explicitly defined, or they are not widely communicated to students. For these systems the more elaborate procedure is needed. The educational rank of an instructional group provides the measure of the "reward" provided by a match of a student to an instructional group. It is the analogue to the job reward in labor market structures.

\section{Causes of closed positions in educational struc- tures}

In the general discussion of closed and open positions three aspects of closed position systems were emphasized as particularly relevant for the allocation process. They were: the predetermined number of positions in closed position systems; the indefinite duration of matches of individuals and positions in such systems; and, that allocation decisions are authority decisions. The reasons for the emergence of the first two of these properties in education systems differ somewhat from the situation in labor markets.

The predetermined numbers and types of instructional groups reflect several characteristics of educational systems. First, educational ideologies, as implemented in curriculum requirements ordered by governments and educational authorities, imply that a minimal set of curriculum units should be provided for. Resources, in the form of number and qualifications of teachers, set other constraints. Most educational systems, in addition, require that the number of students in instructional groups cannot go below or above certain limits. Not only pedagogical concerns, but also the physical lay-outs of school buildings constrain the number of places available in instructional groups. Available equipment forms other constraints. Together, these constraints limit the ability of schools to vary the kinds of instructional groups that may be offered and the number of places in these groups.

Schools usually draw their student from a specific geographical area. Considerable variation may exist in the composition of student bodies with respect to abilities and interests. The size and type distributions of instructional groups do not usually closely reflect this composition. The number, types, and sizes of instructional groups is determined quite, though not totally, independently of the characteristics of those who are to fill the empty places. This proposition should not be controversial for classroom and track groupings in most primary and secondary schools (higher education may to some extent be an exception though student interests do not solely determine course offerings either). It is, perhaps, more intriguing that also in the case of within classroom groupings is the size distribution of groups to be regarded as quite independent of the student body from which ability groups and the like are formed.

When teachers form within classroom groups, they could, in principle, let the number and sizes of groups accomodate the composition of students in the class. In ability grouping, this would imply the size distribution of groups would mirror the ability distribution of students. Ability groups would be of unequal sizes (unless by some fiat the ability distribution is uniform), as small or large as needed to maximize homogeneity. But, such an arrangement runs counter to other considerations the teacher has to make. One consideration is the teacher's ability to manage inattention. This precludes groups that are large and also too many groups. The other consideration is the need to be able to divide instructional time roughly equally among students and groups. Together these considerations imply few, rather than many, groups within the classroom (three to five, it appears) and groups that are of roughly equal sizes. There is evidence the managerial considerations, in fact, override any attempt to make the size distribution of ability groups mirror the ability distribution of students (Hallinan/S $\phi r e n s e n ~ 1982$; Eder 1979). In other words, also instructional groups formed within the classroom may be seen as representing a set of predetermined places to be filled by students, when they are vacant.

The relative independence of the instructional grouping system and the composition of the student bodies allocated to these groups is only a necessary, but not a sufficient, condition for places in instructional groups to be 
considered closed positions. The closed nature of instructional groups reflects curriculum relations and organizational constraints on mobility among existing groups.

If instructional groups are arrayed by their educational ranks, as defined earlier, access to higher groups from lower groups after they have been formed is often prevented by curriculum differences between high and low groups. This holds true both for between classroom groupings and within classroom groupings. In the latter case, the very rationale for ability grouping usually is to accomodate teaching materials to the aptitudes of students.

\section{Downward moves from high to low groups} during the year is not always prevented by teaching materials. Nevertheless, there are strong limits to how frequently it can be done. Only creating downward mobility would change the size distribution of instructional groups. Too many moves are prevented by the forces creating this distribution to begin with. To this only adds the influence of parental pressures and uncertainty about the reliability of performance fluctuations, making it uncomfortable for teachers to demote students. These organizational constraints on mobility, in between the times when groups are established, have been documented for within classroom groupings by Hallinan and Sфrensen (1982). In fact, in her qualitative study, Eder (1979) found that teachers would rather reinterpret performance than move students. Rosenbaum (1976) appears to provide a picture of much downward mobility among high school tracks. But, within and between academic year movements are confounded. The process might as well be described as a promotion system leaving more and more students without promotion chances in what Rosenbaum refer to as "tourn. ament mobility".

In sum, students once assigned to instructional groups are unlikely to be reassigned. Their stay in these groups are not indefinite as in labor market positions, where jobs are vacated only when incumbents leave for promotions. But, the duration of a match is arbitrary in relation to the performance and efforts of students.

The analogy between the closed nature of positions in labor market structures and the closed nature of positions in schools may be made stronger. Recall, the relations defining educational structures are temporal relations. One may define a particular temporal configurations of instructional groups, or an educational trajectory, as elements of this structures. These trajectories may be considered relatively closed for two reasons.

First, the curriculum relations existing between instructional groups constrain and define assign. ments over time, including between the times instructional groups are formed. Earlier curricula are requirements for later curricula. This prevents access to "higher" trajectories from "lower" trajectories over the schooling period. Movement in the other direction is perhaps more feasible, though again the basic constraints imposed by the inflexibility of the size distribution of instructional groups are of some importance. This would still provide a conception of schools as characterized by mobility in the opposite direction of what is observed in closed labor market structures, where promotions are the rule. However, when we move from lower to higher educational levels one also moves from more comprehensive instructional groups to less comprehensive groups. Those instructional groups with the highest ranks thus typically have the most elaborate requirements. Viewed in this manner, the sorting of students in schools may be seen as a promotion system.

Second, early assignments provide signals about competencies and abilities influencing later allocations to instructional groups, even when formal curriculum requirements are not present. As in other closed systems the ability to predict performance is of the essence in assignments to instructional groups of different educational ranks. There is considerable uncertainty and, in some cases, much outside pressure on those performing assignments. Past assignments form one, apparently reliable, indicator of what the student can do, and they create expectations, in students and parents, that teachers can be made aware of.

Perfectly closed educational trajectories run counter to ideology, especially in the US. Schools may institute procedures to modify the long term effects of early assignments on later 
assignments. It is common to change teachers at every grade level in US schools. Still, the receiving teachers obtain information from the teachers left. Eder (1979) reports that first grade teachers relied heavily on information provided by kindergarten teachers when forming reading groups in first grade.

The use of elective assignments at secondary educational levels is another device to break up the effect of early assignments on later assignments. Nevertheless, the freedom of choice may appear greater than it is in reality. Cicourel and Kitsuse (1963) vividly describe the strong influence, in a high school, counsellors and teachers have on student choices and show how they direct these choices so available places get filled without changing the size distribution of instructional groups. To this is added the role of curriculum requirements discussed earlier.

\section{Assignment to instructional groups as vacancy competition}

Configurations over time in sizes of instructional groups define opportunities for students as they move through the educational structure. There are particular historical and organizational circum stances that may strongly influence these opportunities. Variations among schools in curricula and size distributions of instructional groups interacts with student body composition to produce historical and organizationally specific opportunity structures. For example, a student with a given level of ability may achieve a college bound trajectory in one setting and not in another, simply because the number of places providing access to higher education differ in the two settings; or, differences in the compositions of student bodies may make access to a particular set of instructional groups easier in one setting than another.

The interdependence between one's own career and the careers of those one is educated with, reflects the use of rankings in the vacancy competition operating in schools. A certain, specific and limited number of places have to be filled. There are a limited number of candidates for these places. Prediction of performance is important. Opportunism is likely. Therefore, schools like to rely on "objective" tests when performing the most important assignments. Though these tests may have stronger metric properties than ordinality, they are inevitably used to produce percentiles so that cut off points can be established that correspond to the number of available places.

Strangely little of this has been incorporated into research on the educational attainment process. There is a voluminous literature on school effects. This literature does not look at how schools process and channel students into educational trajectories, but on how much variance global school characteristics add to individual level attributes in explaining levels of academic achievement.

There is some research on the effect of tracking (Alexander/McDill 1976) but this literature focuses on additive effects in models that do not reflect the interaction between educational trajectories and rankings in vacancy competition. Qualitative research (e.g. Rosenbaum 1976) does suggest the usefulness of some of the ideas presented here.

A simple example, showing the metric implications of vacancy competition, is available (Sфrensen/Hallinan 1982). In a study of the assignment of students to reading ability groups in 34 classrooms, one question was the effect of race on assignments. These classrooms varied considerably in racial composition. Using as the dependent variable the probability of getting assigned to a high ability group, logit models were estimated. The analysis first fitted a "conventional" model. Here the probability of being assigned to the high group is seen as determined by the reading achievement of the student (measured at the start of the school year) and the race of the student. The reading achievement variable was first measured in the usual metric for such tests (standardized scores, using national norms).

With the "conventional" model the results appear to be: a strong effect of race in favor of non-blacks; and a strong interaction effect between race and achievement. The interaction effect presumably means objective reading achievements are used differently for blacks and nonblacks in the assignment to reading ability groups. Further analysis established strong, but 
difficult to interpret, effects of classroom characteristics, such as racial composition and grade level.

A change in metric produces dramatically different results. The vacancy competition conconception implies teachers use rankings of students in particular classes when performing reading group assignments. To capture this, within classroom achievement distributions were obtained and the percentile ranks in these distributions used as the metric for achievement. This produces a significantly better fit of the model (for example, the chi-square for a model with only race and reading achievement in the conventional metric is 699.8 ; while with the percentile metric it was 639.5 ; degrees of freedom were the same, 573). With the change in metric the interaction between race and achievement disappears, in fact the effect of race on assignment disappears altogether. The first results were an artifact of using the wrong metric. The metric also eliminates the, difficult to interpret, classroom effects. Part of this comes about also through the incorporation of another variable inspired by the vacancy competition model: a variable measuring the relative sizes of the high groups in the various classrooms, or the number of empty places to be filled.

These results show the usefulness of elementary ideas inspired by the vacancy competition conception of the allocation of students to places in instructional schools. The results obviously need elaboration and extensions in future research.

Research on assignments processes and research on educational careers are not the only areas of research in schools where vacancy competition ideas should be useful. The interdependence of outcomes created by the allocation of a limited number of students to a predetermined number of places should have consequences for student efforts. As already noted, the same set of outcomes can be produced in vacancy competition at high effort levels and at low effort levels. Schools may be less concerned than firms about overall performance. They are therefore not likely to invent elaborate incentive devices by complicating promotion systems. This poses performance problems to which solutions are proposed by turning schools into open position market structures in voucher systems. Whether this is feasible remains to be seen. However, despite a considerable amount of research on peer group effects and the like, little is know, expect for the possible existence of "frog pond" effects, about how the interdependence of allocation outcomes create strategic behaviors of students and collective manipulations of effort levels in schools.

\section{Conclusion}

In conclusion, I would like to point to a few consequences of the discussion presented here for our understanding of much used concepts in sociological attainment research. Opportunity, inequality of opportunity, and inequality are terms used with very high frequency in sociological attainment research. The nature of the phenomena they denote and the interrelation among these phenomena depends on whether systems consist of open or of closed positions.

Opportunity has a well defined meaning in closed position systems. An opportunity is an empty space or a vacancy to be filled by someone. Upward mobility predominates in such systems, each vacancy represents a favorable occasion for someone, and this seems to be the sense in which opportunity is understood by most. There is an interesting and important relation between the number of opportunities a system provides, in a period of time, and the degree of inequality of the system. This can be seen from the specification of the vacancy competition model described above. An exponential distribution of positions by the attainment level they provide is assumed. The variance of this distribution, as defined before, is $(-1 / \beta)^{2}$, where $\beta$ is negative. Hence the closer $\beta$ is to zero the more inequality there is in the system. But, the number of opportunities provided by the system is characterized as $b=\beta / h^{6}$. Hence, for given $h$, the more inequality there is, the more opportunities for growth in socioeconomic attainment.

More unequal systems provide more promotion opportunities, at least if they have the hierarchi-

6 Recall that the smaller $b$ is in absolute magnitude, the more opportunities there are. 
cal structure assumed here. Promotion opportunities represent incentives. One may see the considerable amount of inequality in personal attainments found in labor markets (inequalities due to capital is another matter), to be created in large organization as deliberate devices to move employee performance from perfunctory to comsummate. Ironically, extreme inequalities are often seen as products of the market. They instead reflect the impossibility of using market mechanisms in certain job structures, and the incentive problems this creates.

The relation between individual attributes and ultimate attainments reflects the opportunity structure. In the specification of the vacancy competition model it was shown that the contribution of an individual attribute to the ultimate level of attainment is measured by $-c_{i} / b$. Here $c_{i}$ measures the weight or contribution to the qualifications of the individual of a single attribute used in the rankings performed in vacancy competition. The observed effect on ultimate attainment will also be dependent on $b$, measuring how many times the individual was ranked. The more opportunities provided by a system, the stronger effects of individual attributes on ultimate attainments will be observed. This has a methodological implication. Much research on the sociology of labor markets looks for "structural" effects that are added to individual level effects. But, if structural effects are produced by internal labor markets, the effects are not additive but interaction effects. The relation between observed effects of individual attributes and the opportunity structure also has an important substantive implication. If any ascriptive characteristics influence the allocation process, the effect of this will be magnified the more opportunities there are. More inequality produces more opportunities for growth that may result in more observed inequality of opportunity.

Inequality of opportunity need not occur in vacancy competition, it is a matter of how individual attributes are used in rankings of candidates for new vacancies. But there is, as noted, a tendency toward inequality of opportunity in such systems because of opportunism problems created by the limited number of vacancies and candidates for these vacancies present in a moment of time. Rankings reflect ascriptive characteristics and if they do so in a consistent manner across promotions, there is no automatic mechanism that will eliminate inequality of opportunity in such systems. One can only observe the performance one has created by past allocation in a particular system.

The nature and interrelation between opportunity, inequality of opportunity, and inequality is very different in open position markets. The concept of opportunity is not well specified in markets. Systematically created favorable occasions do not exist in perfect markets. This is the rationale for the argument by Hayek regarding the impossibility of competition in perfect markets, already noted. Opportunities are, when they do occur, market imperfections. But such imperfections are, at least, thought to be transient. They have no long term effects on the attainments of individuals, they merely create error terms in attainment models, and indeed the attainments of individuals are not influenced by their past attainment histories. Markets in equilibrium are static systems providing wage rates measuring the performance of individuals at the point : in time at which they are observed. Inequalities are produced outside of the market, in the acquisition of human capital and in genetic endowments. The importance of individual attributes is not cumulative, and there is no need to establish incentive procedures. Wage rates are attached to individuals, so no one is paid more than markets say they contribute. It is difficult to innagine a relation between the number of market imperfections, supposed to be transient, and the degree of inequality in the attainment distribution. Such a relationship may exist between opportunities for acquiring human capital in institutions outside of the market, in particular the family, and inequality. This presents a major rationale for the concern for the intergenerational transmissions of socioeconomic resources. It is to be noted, however, that most of the opportunities for acquiring human capital are provided by closed position school systems, where vacancy competition also govern outcomes.

It is well known that markets are supposed to eliminate inequality of opportunity. Employers, who use attributes of individuals in the allocation process not reflecting productivity, will be punished by the market. There are automatic 
checks to eliminate discrimination. The number of opportunities in the system and the degree of inequality of opportunity are unrelated in markets. Whatever appears to be inequalities of opportunity are produced outside of markets in ascriptive allocations of human capital and genet. ic endowments.

Closed position systems - because of interdependence of outcomes and ranking, idiosyncra- tic mobility regimes, and strong effects of past histories - are perhaps both more interesting and more frustrating than markets. Perfectly competitive markets are not very interesting, one has only oneself to blame for one's attainment. Other virtues and faults of the two systems are discussed at length by others.

\section{References:}

Alexander, K.L./E.L. McDill, 1976: Selection and allocation within schools. American Sociological Review 41: $963-80$.

Baron, J.N./W.T. Bielby, 1980: Bringing the firms back in: stratification, segmentation, and the organization of work. American Sociological Review 47: 175-88.

Bartholomew, D.J., 1973: Stochastic Models for Social Processes. 2nd ed. London: Wiley.

Beck, E.M./P.M. Horan/C.M. Tolbert, 1978: Stratification in a dual economy: a sectoral model of earnings determination. American Sociological Review 43: $704-20$.

Beck, E.M./P.M. Horan/C.M. Tolbert, 1980: Social stratification in a dual economy: further evidence for a structural alternative (reply to Hauser). American Sociological Review 45: 712-19.

Becker, G.S., 1964: Human Capital. New York: NBER. Becker, G.S., 1971: The Economics of Discrimination. 2nd ed. Chicago: $U$. of Chicago.

Berg, I., 1981 : Introduction. In: I. Berg (ed.), Sociological Perspectives on the Labor Market. New York: Academic.

Bielby, W.T./R.M. Hauser/D.L. Featherman, 1977: Response errors of black and nonblack males in models of the intergenerational transmission of socioeconomic status. American Journal of Sociology 82: $1242-88$.

Blau, P.M./O.D. Duncan, 1967: The American Occupational Structure. New York: Wiley.

Boudon, R., 1974: Education, Opportunity, and Social Inequality. New York: Wiley.

Cain, G.G., 1976: The challenge of segmented labor market theories to orthodox theory. Journal of Economic Literature 14: $1215-57$.

Cicourel, A.V./J.I. Kitsuse, 1963: The Educational Decision Makers. Indianapolis: Bobbs-Merrill.

Dahrendorf, R., 1959: Class and Class Conflict in Indus trial Society. Stanford: Stanford U.

Doeringer, P.B./M. Piore, 1971: Internal Labor Markets and Manpower Analysis. Lexington: Heath.

Dunlop, J.T., 1957: The Theory of Wage Determination. London: Macmillan.

Eder, D.J., 1979: Stratification within the classroom: the formation and maintenance of ability groups. Unpublished Disseration, University of Wisconsin Madison.
Goldthorpe, J.H./K. Hope, 1972: Occupational grading and occupational prestige. In: K. Hope (ed.), The Analysis of Social Mobility: Methods and Approaches. Oxford: Clarendon.

Grannovetter, M., 1981: Toward a sociological theory of income differences. In: I. Berg (ed.), Sociological Perspectives on the Labor Market. New York: Academic.

Hallinan, M.T./Aa. B. S $\phi$ rensen, 1982: The formation and stability of instructional groups. Paper presented at the American Sociological Association Meetings. Toronto, 1981. Revised.

Hayek, F.A., 1948: The meaning of competition. In: Individualism and Social Order. Chicago: U. of Chicago.

Hirsch, F., 1976: The Social Limits to Growth. Cambridge: Harvard $U$.

Hodson, R.D., 1978: Labor in the monopoly, competitive and state sector of productions. Politics and Society 8: 429-80.

Kalleberg, Al. L./Aa. B. S $\phi$ rensen, 1979: The sociology of labor markets. Annual Review of Sociology 5: $351-79$.

Kemeny, J.G./J.L. Snell, 1960: Finite Markov Chains. New York: Van Nostrand.

Kerr, C., 1950: Labor markets: their characteristics and consequences. American Economic Review 40:278-91.

Konda, S.L./S. Stewman, 1980: An opportunity labor demand model and Markovian labor supply models: comparative tests in an organization. American Sociological Review 45: 276-301.

Mill, J.S., 1900: Principles of Political Economy. Vol. I. New York: Colonial.

Mincer, J., 1970: The distribution of labor incomes: a survey. Journal of Economic Literature 8: 1-26.

Mincer, J., 1974: Schooling, Experience and Earnings. New York: NBER.

Myles, J.F./Aa. B. Sфrensen, 1975: Elite and status attainment models of inequality of opportunity. Canadian Journal of Sociology 1: 75-88.

Ossowski, S., 1963: Class Structure in the Social Consciousness. London: Routledge \& Kegan Paul.

Pigou, A.C., 1932: The Economics of Welfare. 4th ed. London: Macmillan.

Rosen, S., 1977: Human capital: a survey of empirical results. In: R.G. Ehrenberg (ed.), Research in Labour Economics. New York: JAI. 
Rosenbaum, R.E., 1976: Making Inequality: The Hidden Curriculum of High School Tracking. New York: Wiley.

Rosenbaum, R.E., 1979: Organizational career mobility: promotion chances in a corporation during periods of growth and decline. American Journal of Sociology 85: $21-48$.

Rosenfeld, R.A., 1980: Race and sex differences in career dynamics. American Sociological Review 45: 583-609.

Simmel, G., 1908: Soziologie. Leipzig: Duncker and C. Humblot.

Simon, H., 1957: The employment relation. In: Models of Man. New York: Wiley.


and the process of attainment. American Sociological Review 40: 456-71.

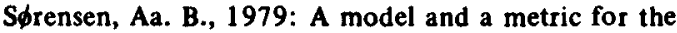
intragenerational status attainment process. American Journal of Sociology 85: 361-84.


job mobility: toward a theory of opportunity and attainment. In: D. Treiman \& K. Tominaga (eds.). Social Stratification in Japan and the United States. New York: JAI.

S $\phi$ rensen, Aa. B., Forthcoming b: The organizational differentiation of students in schools. In: $\mathrm{H}$. Oosthoek \& P. v.d. Eeden (eds.), Multilevel Aspects of the Educational Process. London: Gordon \& Breach.

S $\phi$ rensen, Aa.B./M.T. Hallinan, 1982: Race effects on assignment to ability groups. Paper presented at the Conference on Student Diversity and the Organization of Instructional Groups, Madison, May 3-4, 1982.

Sorensen, Aa.B./A.L. Kalleberg, 1981: Outline of a theory for the matching of persons of jobs. In: I. Berg (ed.), Sociological Perspectives on the Labor Market. New York: Academic.

Sorensen, Aa. B./N.B. Tuma, 1981: Labor market structures and job mobility. In: D.J. Treiman/ R.V. Robinson (eds.), Research in Social Stratification and Mobility. New York: JAI.

Stinchcombe, A.L., 1974: Creating Efficient Industrial Administrations. New York: Academic.

Thurow, L.C., 1975: Generating Inequality. New York: Basic.

Weber, M., 1956: Wirtschaft and Gesellschaft. Tübingen: J.C.B. Mohr (Paul Siebeck).

White, H.C., 1970: Chains of Opportunities. Cambridge: Harvard U.

Williamson, O.E., 1975: Markets and Hierarchies: Analysis and Antitrust Implications. New York: Free.

Wright, E.O., 1979: Class Structure and Income Determination. New York: Academic. 